\title{
Development of an in vitro test for screening of chelators of uranium
}

\author{
O. Braun ${ }^{1}$, C. Contino ${ }^{1}$, M.-H. Hengé-Napoli2,*, E. Ansoborlo² and B. Pucci ${ }^{1, *}$ \\ ${ }^{1}$ Laboratoire de Chimie Bioorganique et des Systèmes Moléculaires Vectoriels, Faculté des Sciences d'Avignon, \\ 33 rue Louis Pasteur, 84000-Avignon, France \\ ${ }^{2}$ Institut de Protection et de Sûreté Nucléaire, Département de Protection de la Santé de l'Homme \\ et de Dosimétrie, Service de Dosimétrie, BP. 6, 92265 Fontenay-aux-Roses Cedex, France
}

\begin{abstract}
This work deals with an in vitro spectrophotometric method to evaluate the chelating ability of various organic ligands for uranyl ion. In this way, an uranium complex formed with a peculiar ligand is chosen as a reference. Any modification of the UV-Visible absorbance of the $\mathrm{U}(\mathrm{VI})$ reference complex, owing to its dissociation upon the addition of a new ligand, permits to compare the affinity of the latter ligand for U(VI) with that of the reference ligand. This test allows to screen easily a lot of ligands before to evaluate their in vivo uranium chelating property.
\end{abstract}

Key words. Uranium (VI) titrimetry - uranium ligands - Chromotrope $2 \mathrm{R}$ complexes.

\section{Introduction}

Uranium under several chemical forms is widely used in the nuclear fuel cycle facilities. After an accidental human contamination, which may be due to a dust inhalation or an uranium salt ingestion, an appropriate treatment could be necessary to accelerate uranium excretion and to reduce its deposition in affected organs, therefore preventing manifestation of related adverse effects. At the present time, the therapy proposed after uranium contamination is still an intravenous injection with a $250 \mathrm{~mL}$ sodium bicarbonate solution (1.4\%) [1] However, because of the limited efficiency of bicarbonate treatment, the development of more effective substances therefore remains an important aspect of radioprotection [2].

The screening of new compounds able to chelate uranyl ion and to permit its body elimination involves a lot of in vivo tests. Studies were conducted using rats and mice on

* Correspondence and reprints.

Received September 11, 1998; revised December 29, 1998; accepted January 06, 1999. 


\section{Original articles}

multidentate catecholate and hydroxypyridonate [3,4], phosphonic acid derivatives [5], phenolic agent like Tiron [6], biphosphonates [7] and tripode phosphorylated [8] compounds. These studies are rather fastidious and expensive. At this step of screening of new compounds, an in vitro test should be sufficient to determine its ability to complex uranium with a higher affinity than bicarbonate, for example.

The aim of this study was to settle an in vitro test for screening the affinity for uranium of new compounds. The accuracy of the test has been checked in measuring the chelating affinity of different molecules considered as references and chosen according to their known ability in chelating uranium in vivo.

This technique allowed a very fast and inexpensive determination of the chelating ability of various compounds.

\section{Method}

\section{Principle}

The complexation property of these compounds with uranium was evaluated in an aqueous buffered solution $(\mathrm{pH}=7)$, using a technique based on competitive complexation [9] and spectrophotometry.

When a metallic ion is complexed with a chromophore chosen as a reference, a measurable modification of its UVvisible absorption spectrum occurs. The absorption difference between the free form of the chromophore and the cation complexed form can be used to specify a chelating property. Indeed, the addition of another complexing agent, which does not absorb in UV at the same wavelength as the reference chromophore, should induce a significant modification of the UV absorption intensity of the chromophore related to their respective chelating ability. In these conditions, the complexation ability of a compound can easily and quickly be compared to that of the reference molecule. Moreover, the result obtained with this chosen reference could be referred to those measured with another one.

The choice of this reference molecule has to comply with a few constraints: solubility and stability in water at physiological $\mathrm{pH}$, high complexation strength of the metal ion and reaction kinetic as fast as possible, great intensity of the absorption spectrum in the UV-visible field and above all measurable modification of the spectrum associated to the complexation in a wavelength field different from those of the chosen metal ion.

In the case of the uranyl ion, the reference compound is derived from chromotropic acid, which was described to have a strong affinity for uranium (VI) [6]. The absorption spectrum of this compound lies in the UV-visible field [6].

When the affinity of the ligand for uranium (VI) is substantially higher than that of the reference ligand Chromotrope $2 \mathrm{R}$, the absorbance measured after addition of a stoechiometric amount of ligand must be that of the pure
Chromotrope $2 \mathrm{R}$. In this case, the complex between uranyl and Chromotrope $2 \mathrm{R}$ is destroyed by the new ligand.

When the affinity of the ligand for uranium is in the same level than that of the Chromotrope 2R, the absorbance should range from the value of the pure Chromotrope $2 \mathrm{R}$ (0.25) to the absorbance of the complexed Chromotrope $2 \mathrm{R}$ (0.5). If this variation is considered as linear and if the stoechiometry of the U(VI)/Ligand complex is the same for the new ligand as for the Chromotrope $2 \mathrm{R}$, the complexation strength (i.e. the conditional stability constant) of the ligand could be estimated, compared to the reference molecule.

When the affinity of the ligand for uranium is clearly weaker than that of the Chromotrope $2 \mathrm{R}$, the equilibrium must remain undisturbed and the absorbance-measured $(0.5)$ corresponds to that of the complexed Chromotrope $2 \mathrm{R}$.

When the ligand tested displaces the Chromotrope 2R complex, it can be assumed that the new complex formed is stronger and that it would be interesting to test this compound in vivo.

Such a method could be generalised to various metal ions if a chromophore compound well-known for its chelating properties can be used as a reference.<smiles>[R20][R]([H])=O</smiles>

\section{Protocol}

Complexation between uranium and Chromotrope 2R:

A $0.1 \mathrm{mM}$ stock solution of the Chromotrope $2 \mathrm{R}$ was prepared in saline and the $\mathrm{pH}$ was adjusted at 7. The absorption spectrum of the solution was measured between 200 and $800 \mathrm{~nm}$. When a solution of uranyl nitrate $\left(\mathrm{UO}_{2}\left(\mathrm{NO}_{3}\right)_{2}\right)$ was added, a modification of the colour of the solution due to the formation of the complex was observed. The difference between the absorption spectrum of the Chromotrope $2 \mathrm{R}$ and the spectrum of the complex was measured. The resulting spectrum exhibited a maximum wave at $580 \mathrm{~nm}$ (Fig. 1). The $\mathrm{pH}$ was adjusted with $20 \mathrm{mM}$ HEPES buffer which did not complex uranium and did not absorb at $580 \mathrm{~nm}$. The intensity of the absorbance peak was correlated to the degree of complexation of the Chromotrope $2 \mathrm{R}$.

It is noteworthy that a neutral solution of uranyl nitrate does not present any absorption at $580 \mathrm{~nm}$.

The reaction and the measure were made in saline $(\mathrm{NaCl}$ $0.9 \%$ in Milli-Q distilled water). This also set the ionic strength of the medium $(I=0.15)$. The spectra were measured with Beckman DU 7500 using single use cells at room temperature. 


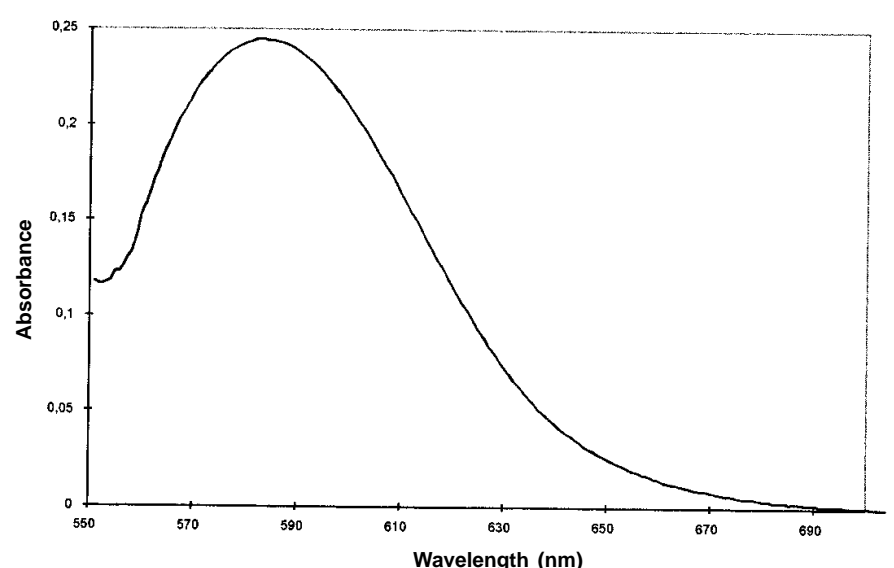

Fig. 1. Difference spectrum of Chromotrope $2 \mathrm{R}$ complexed to $\mathrm{U}(\mathrm{VI})$ at $20{ }^{\circ} \mathrm{C}$ between: - sample: Chromotrope 2R: $0.166 \mathrm{mM}$, $\mathrm{U}(\mathrm{VI}): 0.083 \mathrm{mM}$, Hepes: $3.3 \mathrm{mM}, \mathrm{pH}=7$ - reference: Chromotrope 2R: $0.166 \mathrm{mM}$, Hepes: $3.3 \mathrm{mM}, \mathrm{pH}=7$.

Destruction of the complex between uranium and Chromotrope $2 \mathrm{R}$ by a ligand:

The following reagents were added in this order: $1 \mathrm{~mL}$ of a $1 \mathrm{mM}$ solution of Chromotrope 2R (Aldrich), $3 \mathrm{~mL}$ of 20

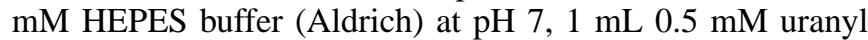
nitrate solution (Prolabo). The solution was mixed, then protected from direct sunlight and left for $15 \mathrm{~min}$. One $\mathrm{mL}$ of the compound to assay was added; its final concentrations in the vial was ranging from $10^{-2}$ to $10^{-7} \mathrm{mM}$. The absorbance of the solution was measured at $580 \mathrm{~nm} 30 \mathrm{~min}-$ utes later.

\section{Results and discussion}

The Chromotrope $2 \mathrm{R}$ is a dye derived from the chromotropic acid. It presents a chelating power for U(VI) [6]. This complexation results in a change of the colour of the solution. The highest difference between the spectra of the free Chromotrope and the U(VI) complex is observed at $580 \mathrm{~nm}$ (Fig. 1).

When the variation of the absorbance of a $0.166 \mathrm{mM}$ Chromotrope $2 \mathrm{R}$ solution versus the amount of added uranium is plotted, the maximum of absorbance is reached after the addition of $0.0833 \mathrm{mM}$ of uranium (Fig. 2). This result indicates that 1 uranyl ion is complexed with 2 Chromophore 2R molecules. This concentration of $0.0833 \mathrm{mM}$ has been retained for the test in order to be certain that the reaction was complete and that there was no free uranium in the solution. As the values of absorbance remain stable during the time, one admits that the equilibrium is reached in all cases.

At the concentration used, uranyl nitrate may precipitate at a $\mathrm{pH}$ higher than 5. It is therefore necessary to respect the order of addition of the reactant in the solution:

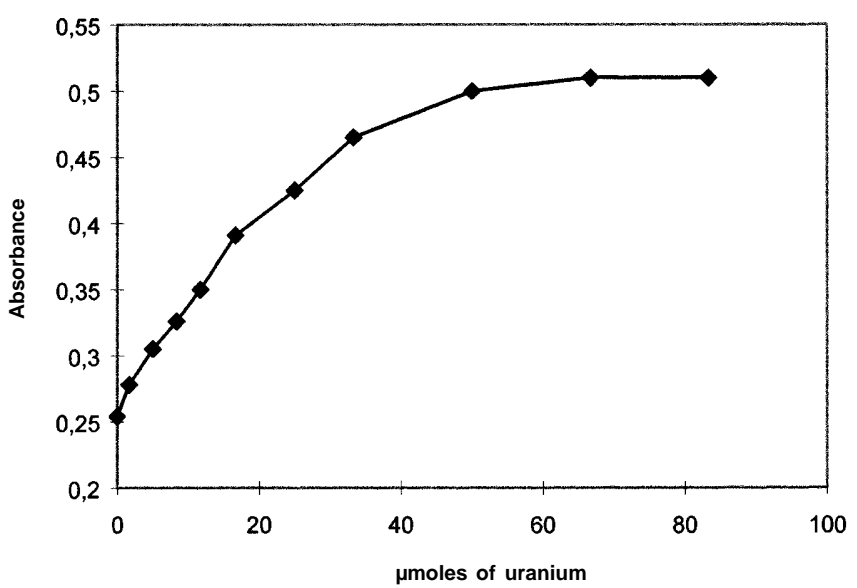

Fig. 2. Variation of the absorbance at $580 \mathrm{~nm}$ of Chromotrope $2 \mathrm{R}$ versus increasing concentrations of uranium $(\mathrm{VI})(\mathrm{pH}=7)$ at $20{ }^{\circ} \mathrm{C}$. Chromotrope 2R: $0.166 \mathrm{mM}, \mathrm{U}(\mathrm{VI})$ : ranging from 0 to $100 \mu \mathrm{M}, \mathrm{pH}=7$; Hepes: $3.3 \mathrm{mM}$.

Chromotrope, HEPES, $\mathrm{UO}_{2}\left(\mathrm{NO}_{3}\right)_{2}$ and at last the ligand. Moreover, at this $\mathrm{pH}$ and for $\mathrm{U}(\mathrm{VI})$ concentrations higher than $0.1 \mathrm{mM}$, the appearance of uranyl microprecipitates should disturb the measure of absorbance [10,11].

When a ligand $\mathrm{L}^{2}$ is added into a solution containing an other ligand $\mathrm{L}^{1}$ (Chromotrope $2 \mathrm{R}$ ) and the cation $\mathrm{UO}_{2}{ }^{2+}$, the following reaction takes place:

$$
\mathrm{L}^{2}+\mathrm{L}^{1} \mathrm{UO}_{2}^{2+} \Leftrightarrow \mathrm{L}^{1}+\mathrm{L}^{2} \mathrm{UO}_{2}{ }^{2+} \text {. }
$$

The protocol described here was applied to some molecules known for their in vivo complexation ability: bicarbonate, Tiron, citric acid and 3,4,3-Li-(1,2-HOPO) [4]:

The results are presented in figures 2 and 3 and call for the following comments:

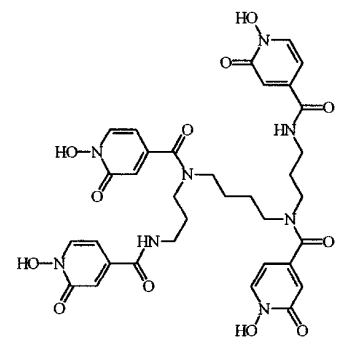

LIHOPO

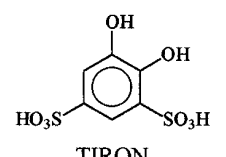

TIRON
- our results show that the bicarbonate ion, which is known as in vivo strong complexing compound, exhibits a rather weak chelating power. The shift of the complex is only obtained with a bicarbonate concentration $\left(10^{-2} \mathrm{M}\right) 100$ times higher than that of the Chromotrope 2R (Fig. 3). The complexing strength observed in vivo could be explained through the mass effect of bicarbonates: indeed the level of bicarbonate administered is very high towards the uranium amount. 


\section{Original articles}

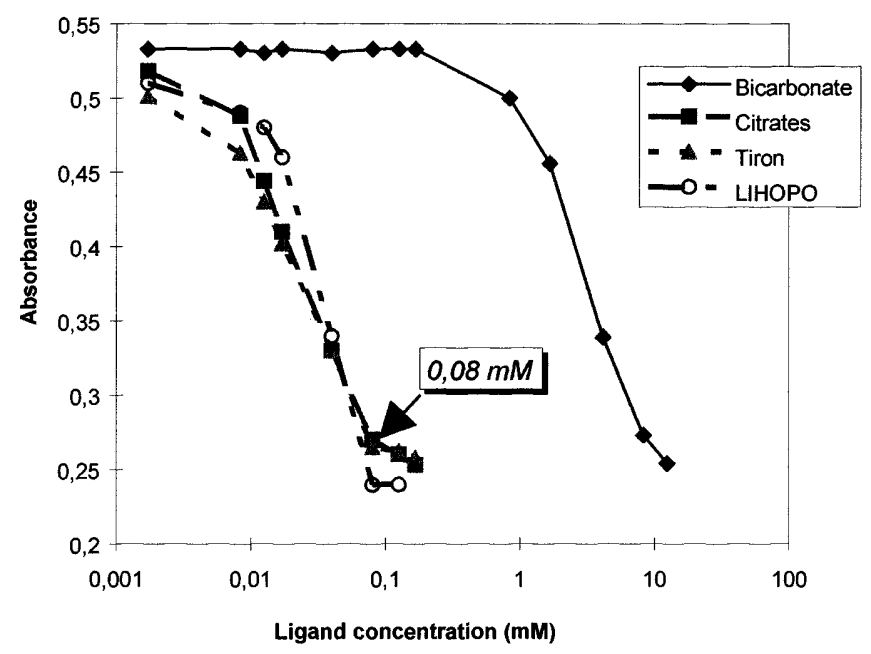

Fig. 3. Variation of the absorbance at $580 \mathrm{~nm}$ of Chromotrope $2 \mathrm{R}$ at $20{ }^{\circ} \mathrm{C}$. Chromotrope 2R: $0.166 \mathrm{mM}$.; uranyl nitrate: $0.0833 \mathrm{mM}$; Hepes: $3.3 \mathrm{mM}$ and Tiron 3,4,3-LI(1,2-HOPO), sodium bicarbonate or citrate at various concentrations $(\mathrm{pH}=7)$.

- Citric acid, Tiron and 3,4,3-Li-(1,2-HOPO) exhibit complexing strengths in the same range of magnitude than Chromotrope $2 \mathrm{R}\left(10^{-4} \mathrm{M}\right)$ (Fig. 3). Our results strongly suggest that 1 uranyl complexes with 1 molecule of $3,4,3-\mathrm{Li}$ (1,2-HOPO). Actually, the complex between uranium and the Chromotrope $2 \mathrm{R}$ is totaly destroyed (absorbance $=0.23$ ) when the concentration of $0.083 \mathrm{mM}$ of $3,4,3-\mathrm{Li}-(1,2-$ HOPO) is achieved in the medium, which is also the concentration of uranium.

- It is underlined that Tiron and 3,4,3-Li-(1,2-HOPO) were tested in vivo. Results obtained showed that both compounds are able to complex the uranyl ion [4].

\section{Conclusion}

After the complexation of uranium with a chosen chromophore, herein the Chromotrope $2 \mathrm{R}$, any modification of the absorption spectrum observed in the solution will be due to a dissociation of the complex. This will be obtained by the addition of a compound having an affinity for uranium at least equivalent to that of the reference ligand. In these conditions, the complexation ability of the added compound can easily and quickly be compared to that of the reference molecule.
The aim of this work was to design a simple test in order to perform a screening of potential uranyl ligands while limiting, as far as possible, the in vivo studies. The idea was to find a good complexing agent of uranium like the Chromotrope 2R, with relevant spectrophotometric properties and to test different ligands already known for their in vivo properties. When the ligand tested displaces the complex, it can be assumed that the new complex formed is stronger and that it is interesting to test that compound in vivo. In most of the cases, this test does not allow the direct determination of the stoechiometry of the complexation, and the comparison between the complexation power of ligands has to be done very carefully.

However, the ranking of potential chelating agents would need the use of a set of different reference compounds having a complexation constant closer to that of the tested ligands.

Finally, it is obvious that this test could be used with other metals since the formation of the complex with a ligand chosen as a reference disturbs the absorption spectrum.

\section{References}

1. Battacharyya, M. H.; Breitenstein, B.; Métivier, H.; Muggenburg, B. A.; Stradling, G. N.; Volf, V. Radiat. Protec. Dosim. 1992, 41, 27-36.

2. Métivier, H. Radiat. Protec. Dosim. 1994, 53(1-4), 291-296.

3. Durbin, P. W.; Kullgreen, B.; Xu, J.; Raymond, K. N. Health Phys. 1997, 72, 865-879.

4. Hengé-Napoli, M. H.; Archimbaud, M.; Ansoborlo, E.; Métivier, H.; Gourmelon, P. Int. J. Radiat. Biol. 1995, 68, 389393.

5. Sradling, G. N.; Gray, S. A.; Moody, J. C.; Burgada, R. EULEP Newslett. 1994, 75, 38.

6. Basinger, M. A.; Forti, R. L.; Burka, L. T.; Jones, M. M.; Mitchell, W. M.; Joyce, E. J.; Gibbs, S. J. J. Toxicol. Environ. Health 1983, 11, 237-246.

7. Ubios, M. A.; Braun, E. M.; Cabrini, R. L. Health Phys. 1994, 66(5), 540-544.

8. Hengé-Napoli, M. H.; Montagne-Marcellin, C.; Archimbaud, M.; Ansoborlo, E. International Congress on Radiation Protection, IRPA9, Vienna, 1996; pp 517-519.

9. Buschmann, H. J. Inorg. Chim. Acta 1992, 195, 51-60.

10. Grenthe, I.; Fuger, J.; Konigs, R. J. M.; Lemire, R. J.; Muller, A. B.; Nguyen-Trung, C.; Wanner, H. In: Chemical thermodynamics of uranium, Wanner and Forest Eds. OECD Nuclear Energy Agency, Data bank, 1992.

11. Palei, N. Israel Program for scientific Translations 1979, 1327/93-168. 